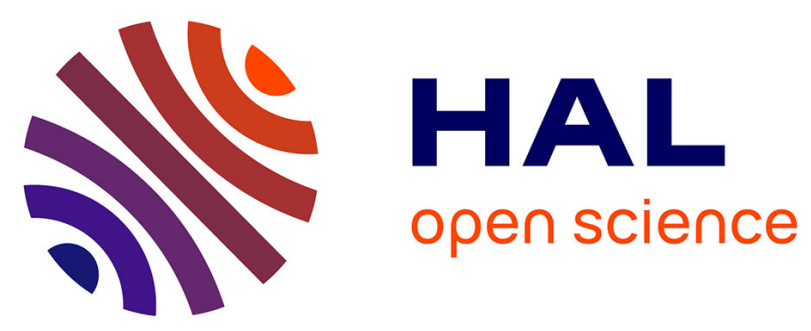

\title{
Pointing to a target while naming it with / pata/ or /tapa/: the effect of consonants and stress position on jaw-finger coordination
}

\author{
Amélie Rochet-Capellan, Jean-Luc Schwartz, Rafael Laboissière, Arturo
}

Galvan

\section{To cite this version:}

Amélie Rochet-Capellan, Jean-Luc Schwartz, Rafael Laboissière, Arturo Galvan. Pointing to a target while naming it with / pata/ or /tapa/: the effect of consonants and stress position on jaw-finger coordination. Interspeech 2007 - 8th Annual Conference of the International Speech Communication Association, Aug 2007, Antwerp, Belgium. pp.634-637. hal-00195361

\section{HAL Id: hal-00195361 \\ https://hal.science/hal-00195361}

Submitted on 10 Dec 2007

HAL is a multi-disciplinary open access archive for the deposit and dissemination of scientific research documents, whether they are published or not. The documents may come from teaching and research institutions in France or abroad, or from public or private research centers.
L'archive ouverte pluridisciplinaire $\mathbf{H A L}$, est destinée au dépôt et à la diffusion de documents scientifiques de niveau recherche, publiés ou non, émanant des établissements d'enseignement et de recherche français ou étrangers, des laboratoires publics ou privés. 


\title{
Pointing to a target while naming it with /pata/ or /tapa/: the effect of consonants and stress position on jaw-finger coordination
}

\author{
Amélie Rochet-Capellan ${ }^{1}$, Jean-Luc Schwartz ${ }^{1}$, Rafael Laboissière ${ }^{2,3}$, Arturo Galvàn ${ }^{2}$ \\ ${ }^{1}$ GIPSA-Lab, Département parole et cognition (ICP, Institut de la Communication Parlée), France \\ ${ }^{2}$ Max Planck Institute for Human Cognitive and Brain Science, Munich, Germany \\ ${ }^{3}$ Espace et Action, U864 INSERM, Lyon, France
}

amelie.rochet-capellandicp.inpg.fr, jean-luc.schwartz@icp.inpg.fr,

laboissiere@cbs.mpg.de, galvan@cbs.mpg.de

\begin{abstract}
This study investigates jaw-finger coordination in a task consisting in pointing to a target while naming it with a $/ \mathrm{pata} /$ or a /tapa/ utterance stressed either on the first ('CVCV) or on the second $\left(\mathrm{CV}^{\prime} \mathrm{CV}\right)$ syllable. Optotrack measurements of jaw and finger displacements show that for 'CVCV names, the moment at with the finger reaches the target alignment is synchronized with the maximum of the first jaw opening motion. For $\mathrm{CV}^{\prime} \mathrm{CV}$ names, the synchronization occurs between the moment at which the finger leaves the target-alignment position and the maximum of the jaw opening motion for the second vowel. This pattern of synchronization does not depend on the target position or on the consonants order. These results add some support to theories involving the coordination of orofacial and brachiomanual gestures in the development and phylogeny of human languages. They call for more investigations on the link between speech and brachiomanual gestures in face-to-face communication.
\end{abstract}

Index Terms: speech-hand coordination, jaw-finger coordination, deixis, pointing, Optotrak.

\section{Introduction}

\subsection{Substance-based deixis}

The deictic function of language (refer to an object) has been assumed to be first supported by the hand and later connected to speech [1][2]. This connection could constitute a substrate for the emergence of language indexical signs (e.g. "this") in the course of ontogeny and phylogeny. Hence, a close link might exist between speech and pointing deictic sites, enabling to show respectively by the hand and by the voice. Synchronization of speech and hand pointing in face-to-face communication [3][4] could consist in coherence between the speech focus and the pointing focus, with a trend to align the arm-hand-finger system with the speech focus. Moreover, developmental studies displayed a link between the frequencies of arm-hand gestures and jaw oscillations in babbling [5]. This link would evolve toward a "rendez-vous" between the motor control of jaw oscillations in babbling, the speech frame [6][7] and brachiomanual oscillations in pointing, the sign frame [8]. This "rendez-vous" would play a key role in language acquisition [9][10]. In addition, it leads to suspect that synchronization between speech and pointing gestures could rest on a close coordination of the jaw and arm-hand oscillatory systems, anchored in motor control acquisition.

\subsection{Focus and jaw-finger coordination}

In this framework, we previously studied jaw-finger coordination in a task consisting in pointing to a target while naming it with a CVCV word (/papa/ vs. /tata/) stressed either on the first ('CVCV) or on the second (CV'CV) syllable [11]. The hypothesis was that the instant of finger-target alignment (pointing apex, $\mathrm{P}_{\mathrm{A}}$ ) would be synchronized with the instant of maximum jaw opening (apex) for the stressed vowel; that is, with the first jaw apex $\left(\mathrm{J}_{\mathrm{A} 1}\right)$ for 'CVCV names and the second one $\left(\mathrm{J}_{\mathrm{A} 2}\right)$ for $\mathrm{CV}^{\prime} \mathrm{CV}$ ones. The results showed that $\mathrm{P}_{\mathrm{A}}$ was actually close to $\mathrm{J}_{\mathrm{A} 1}$ for 'CVCV names. For $\mathrm{CV}^{\prime} \mathrm{CV}$ ones, $\mathrm{P}_{\mathrm{A}}$ occurred after $\mathrm{J}_{\mathrm{A} 1}$, but before $\mathrm{J}_{\mathrm{A} 2}$, roughly at an equal delay between $\mathrm{J}_{\mathrm{A} 1}$ and $\mathrm{J}_{\mathrm{A} 2}$, contrary to the prediction. However, in that case, $\mathrm{J}_{\mathrm{A} 2}$ was synchronized with the end of the period of finger-target alignment, when finger began its return stroke. Hence, there seems to be clear jaw-finger coordination, though different from our original hypothesis. The effect of stress position on finger-jaw synchronization mainly results from a speech adaptation: jaw movement begins earlier for $\mathrm{CV}^{\prime} \mathrm{CV}$ than for 'CVCV names. However, it also involves the duration during which the finger points on the target: the finger stays longer in its apex position for $\mathrm{CV}^{\prime} \mathrm{CV}$ than 'CVCV names, "expecting", in some sense, jaw arrival on the stressed vowel. Further analyses showed that stress modifies amplitude and duration of the two jaw opening gestures, but has no effect on initiation and apex times of the pointing gesture. Conversely, increasing target distance delays both pointing apex and jaw apices, but has no effect on amplitude and duration of the two jaw opening strokes. Altogether, this previous experiment showed that the speech focus tends to be achieved during the finger-target alignment and that jaw events tend to be anchored in pointing events. Moreover, the pointing gesture aims at reaching the target alignment; it is mainly "target-driven". On the contrary, jaw motions are adapted both to the phonetic goal and to the pointing task.

\subsection{Jaw profiles and jaw-finger coordination}

The previous study used CVCVs words with a single consonantal articulation place. However, in another study focused on jawtongue-lips coordination in speech sequences, we found different jaw motion profiles in duplicated (/tata/-/papa/) vs. variegated (/pata/-/tapa/) utterances produced with rate increase [12][13]. The main tendency is to realize variegated $\mathrm{CVCV}$ sequences with large asymmetries between the two jaw cycles, evolving towards a single jaw cycle with rate increase. On the contrary, duplicated CVCV always required two jaw cycles. The present study aims at testing if the pattern of jaw-finger coordination observed with /papa/ and /tata/ with different stress positions resists to the 
modifications in jaw dynamics imposed by variegation in /pata/ and /tapa/ sequences. This would provide an argument for the independence of internal speech planning relative to the adaptation of speech gestures to pointing gestures.

\section{Methods}

Participants. Twenty native Brazilian Portuguese speakers (4 men and 16 women), right-handed with normal or correctedto-normal vision, participated in the experiment. The Brazilian Portuguese language was chosen because it is possible to find pairs of words in this language that differ only by the position of the stress. The participants and the procedure were the same as those of our previous study [11].

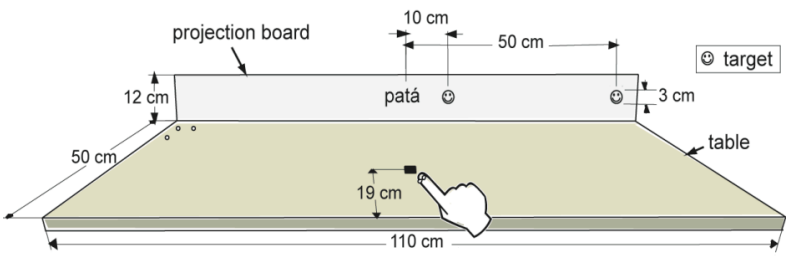

Figure 1. Experimental setup

Procedure. The participant was seated at a table. She/he was informed that a word and a red smiley (:) sign (the target) would appear on the board in front of her, projected by a beamer. The word was introduced as the name of the person represented by the smiley-target. It could be either/pata/ or /tapa/ with a stress on the first (e.g. /pàta/) or on the second (e.g. /patà/) vowel. The vowel /a/ was selected since its realization requires a large jaw opening gesture. The target appeared in the right visual field, either at the near or at the far position (see Figure 1). The task was to point to the smiley and name it with the word as soon as its color changed from red to green. The presentation of the red target lasted for $3.5 \mathrm{~s}$ plus a Gaussian variation with zero mean and $0.15 \mathrm{~s}$ standard deviation. Then, the target became green (the GO signal) and lasted $1 \mathrm{~s}$ on the board. A black square on the midline of the table indicated the onset position for the finger-pointing gesture. The experiment was divided into four blocks separated by a 30 s pause. A block contained 4 practice trials and 40 experimental trials, 10 for each [stress position]*[target position]*[consonants order] experimental condition. The order of the trials was randomized for each block and each participant.
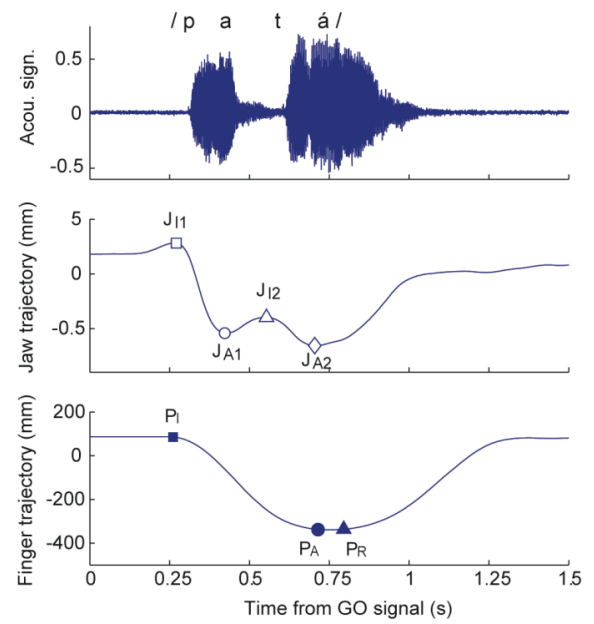

Figure 2. Record and labeling for a /patà/ trial.
Data recording and processing. Finger and jaw movements were recorded using an Optotrak. Two markers were pasted at the tip of index finger, such that at least one of them was always visible by the cameras during the course of the pointing movement. The jaw position was tracked by a third marker attached to the chin. Three other markers were pasted on the table to provide a referential for the moving markers. Head motion was measured by three markers attached to a plastic triangle fixed around the subject's head. Jaw positions were computed in relation to the head moving reference frame. The markers positions were sampled against time at $100 \mathrm{~Hz}$. In order to reduce the amount of data to process, we conducted a Principal Component Analysis (PCA) on the Optotrak data. The first principal component appears as a good representation of markers motions. In average, for the 20 participants, it explained $98 \%$ of the variance for the finger markers and $95 \%$ for the jaw marker. These signals were lowpass filtered at $15 \mathrm{~Hz}$ with a Butterworth filter. The temporal measurements are indicated in Figure 2. Motion onset (initiation) and apex times correspond to $10 \%$ of the peak velocity at the beginning and the end of the movement, respectively. $\mathrm{P}_{\mathrm{I}}$ and $\mathrm{P}_{\mathrm{A}}$ are the initiation and apex times for the forward movement of the finger, while $P_{R}$ is the onset of the return movement. For the jaw, $\mathrm{J}_{11}, \mathrm{~J}_{\mathrm{A} 1}$ and $\mathrm{J}_{12}, \mathrm{~J}_{\mathrm{A} 2}$ are the initiation and the apex times of the first and second opening gestures, respectively.

\section{Results}

Absolute positions of jaw and finger events are displayed in Figure 3. As in [11], we also computed positions of $P_{A}$ and $P_{R}$ relative to the two jaw apices, defined as:

$$
\mathrm{P}_{\mathrm{A} / \mathrm{J}}=\left(\mathrm{P}_{\mathrm{A}}-\mathrm{J}_{\mathrm{A} 1}\right) /\left(\mathrm{J}_{\mathrm{A} 2}-\mathrm{J}_{\mathrm{A} 1}\right) \text { and } \mathrm{P}_{\mathrm{R} / \mathrm{J}}=\left(\mathrm{P}_{\mathrm{R}}-\mathrm{J}_{\mathrm{A} 1}\right) /\left(\mathrm{J}_{\mathrm{A} 2}-\mathrm{J}_{\mathrm{A} 1}\right)
$$

A value of 0 (respectively 1 ) indicates that the finger event is synchronized with $\mathrm{J}_{\mathrm{A} 1}$ (respectively $\mathrm{J}_{\mathrm{A} 2}$ ). Finger positions relative to jaw apices are displayed in Figure 4. Amplitude and duration of jaw and finger strokes, were also computed as the difference of position and duration between the initiation and the apex of the stroke, respectively. They are displayed in Figure 5. The effects of the three experimental factors on each measure were tested using three-way within-subject ANOVAs (effects are considered significant for $\mathrm{p}<.05$ with $\mathrm{F}(1,19)$ ).

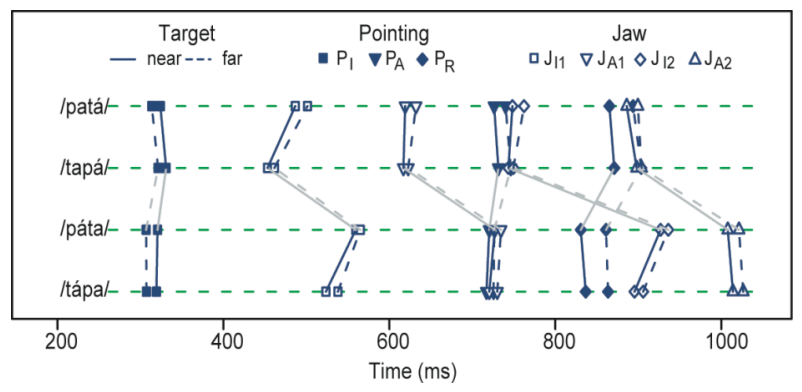

Figure 3. Mean durations from the GO-signal to jaw and finger events according to experimental conditions.

\subsection{Pattern of jaw-finger synchronization}

The effect of stress position on $\mathrm{P}_{\mathrm{A} / \mathrm{J}}$ is significant, with $\mathrm{P}_{\mathrm{A} / \mathrm{J}}$ smaller for 'CVCV $(-0.02)$ than for $\mathrm{CV}^{\prime} \mathrm{CV}(0.41)(\mathrm{p}<.0001)$. The effect of stress position on $\mathrm{P}_{\mathrm{R} / \mathrm{J}}$ is also significant, with $\mathrm{P}_{\mathrm{R} / \mathrm{J}}$ smaller for 'CVCV (0.44) than for $\mathrm{CV}^{\prime} \mathrm{CV}$ (0.95) $(\mathrm{p}<.0001)$. Target position and consonant order effects on $\mathrm{P}_{\mathrm{A} / \mathrm{J}}$ are not significant, but $\mathrm{P}_{\mathrm{R} / \mathrm{J}}$ depends on the target position 
with greater value in the far $(0.73)$ than in the near $(0.66)$ target condition $(\mathrm{p}<.01)$. Interaction effects are not significant.

Hence, the synchronization pattern is similar to the one found previously [11]. Firstly, the pointing apex is close to the first jaw apex for 'CVCV sequences while it occurs at about an equal delay from the two jaw apices for $\mathrm{CV}^{\prime} \mathrm{CV}$ ones. Secondly, the pointing return occurs close to the second jaw apex for $\mathrm{CV}^{\prime} \mathrm{CV}$ names while it occurs at about an equal delay from the two jaw apices for 'CVCV ones. This pattern of synchronization does not depend on target position or consonant order.
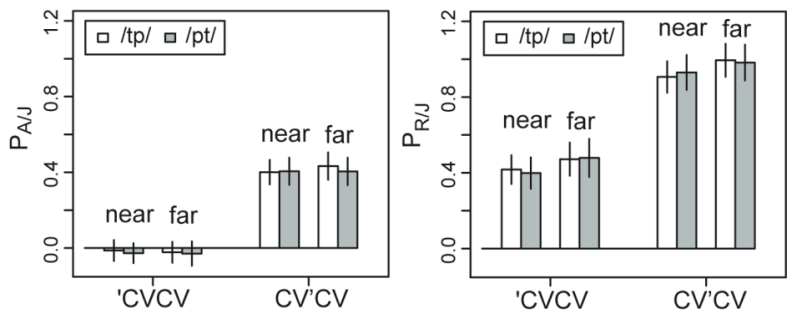

Figure 4. Position of pointing apex $\left(\mathrm{P}_{\mathrm{A} / \mathrm{J}}\right.$, left $)$ and pointing return onset $\left(\mathrm{P}_{\mathrm{R} / \mathrm{J}}\right.$, right $)$ relatively to jaw apices according to experimental conditions.

\subsection{Finger motion}

Increase in target distance results in a significant $11 \mathrm{~ms}$ advance of $\mathrm{P}_{\mathrm{I}}$, and a significant delay of $\mathrm{P}_{\mathrm{A}}$ and $\mathrm{P}_{\mathrm{R}}$ (respectively $11 \mathrm{~ms}$ and $30 \mathrm{~ms}, \mathrm{p}<.05$ ). Thus, the pointing forward motion (from $\mathrm{P}_{\mathrm{I}}$ to $\mathrm{P}_{\mathrm{A}}$ ) is $20 \mathrm{~ms}$ longer in the far- than in the near- target condition $(\mathrm{p}<.0001$; Figure 5, top right). The stroke amplitude is also $147 \mathrm{~mm}$ greater in the far- than in the near- target condition $\left(\mathrm{p}<.0001\right.$, Figure 5 , top left). Finally, the plateau $\left(\mathrm{P}_{\mathrm{R}}-\mathrm{P}_{\mathrm{A}}\right)$ duration is $19 \mathrm{~ms}$ longer in the far- than in the near- target condition $(\mathrm{p}<.01$, see Figure 3$)$.

The stress position has no significant effect on $\mathrm{P}_{\mathrm{I}}$ and $\mathrm{P}_{\mathrm{A}}$ and on the amplitude and the duration of the forward motion. On the contrary, $\mathrm{P}_{\mathrm{R}}$ is $35 \mathrm{~ms}$ later for $\mathrm{CV}^{\prime} \mathrm{CV}$ than for ' $\mathrm{CVCV}$ sequences $(\mathrm{p}<.001)$. Hence the plateau $\left(\mathrm{P}_{\mathrm{R}}-\mathrm{P}_{\mathrm{A}}\right)$ duration is $22 \mathrm{~ms}$ longer for $\mathrm{CV}^{\prime} \mathrm{CV}$ than 'CVCV sequences $(\mathrm{p}<.001)$.

The consonant order has no significant effect on $\mathrm{P}_{\mathrm{I}}$ and $\mathrm{P}_{\mathrm{A}}$ and on amplitude and duration of the forward motion. Then, this factor has a significant but weak effect on the $\left(\mathrm{P}_{\mathrm{R}}-\mathrm{P}_{\mathrm{A}}\right)$ duration (4 ms longer for $/ \mathrm{tp} /$ than $/ \mathrm{pt} /, \mathrm{p}<.05$ ).

No interaction effect is significant.

Altogether, the finger forward motion just depends on the target position. Then, once the alignment with the target is achieved, the plateau duration adapts to the stress position: the finger can wait for the jaw.

\subsection{Jaw motion}

Figure 3 shows that all jaw events $\mathrm{J}_{\mathrm{I} 1}, \mathrm{~J}_{\mathrm{A} 1}, \mathrm{~J}_{\mathrm{I} 2}$ and $\mathrm{J}_{\mathrm{A} 2}$ occur significantly earlier for $\mathrm{CV}^{\prime} \mathrm{CV}$ than 'CVCV names $(\mathrm{p}<.001)$. The $\mathrm{J}_{\mathrm{A} 1}$ to $\mathrm{J}_{\mathrm{A} 2}$ duration is larger for ' $\mathrm{CVCV}$ utterances $(290 \mathrm{~ms})$ than for $\mathrm{CV}^{\prime} \mathrm{CV}$ ones $(275 \mathrm{~ms})$. Duration of the first jaw motion is $35 \mathrm{~ms}$ greater for ' $\mathrm{CVCV}$ than for $\mathrm{CV}^{\prime} \mathrm{CV}$ utterances $(\mathrm{p}<.0001)$. Conversely, the second jaw motion is $44 \mathrm{~ms}$ longer for $\mathrm{CV}^{\prime} \mathrm{CV}$ than for 'CVCV utterances $(p<.0001)$. Similarly, the amplitude of the first stroke is $3.1 \mathrm{~mm}$ larger for ' $\mathrm{CVCV}$ than for $\mathrm{CV}^{\prime} \mathrm{CV}$ utterances $(p<.0001)$ while the amplitude of the second stroke is $3.8 \mathrm{~mm}$ larger for $\mathrm{CV}^{\prime} \mathrm{CV}$ than for ' $\mathrm{CVCV}$ utterances $(\mathrm{p}<.0001)$. The consonant order has a significant effect on $\mathrm{J}_{\mathrm{I} 1}$ and $\mathrm{J}_{\mathrm{I} 2}$, occurring respectively $34 \mathrm{~ms}(\mathrm{p}<.001)$ and $20 \mathrm{~ms}(\mathrm{p}<.01)$ earlier for $/ \mathrm{tp} /$ than for $/ \mathrm{pt} /$, but no significant effect on $\mathrm{J}_{\mathrm{A} 1}$ and $\mathrm{J}_{\mathrm{A} 2}$. It does not significantly affect the first stroke amplitude while the second stroke is $3.2 \mathrm{~mm}$ larger for $/ \mathrm{tp} /$ than $/ \mathrm{pt} /(\mathrm{p}<.0001)$. Furthermore, the first and second jaw strokes are, respectively, $29 \mathrm{~ms}(\mathrm{p}<.001)$ and $26 \mathrm{~ms}(\mathrm{p}<.0001)$ longer for $/ \mathrm{tp} /$ than $/ \mathrm{pt} /$ The interaction between stress and consonant order is significant only for $\mathrm{J}_{12}$ with a greater stress effect for $/ \mathrm{pt} /$ than for $/ \mathrm{tp} /$ $(\mathrm{p}<.05)$.

Jaw events occur about $10 \mathrm{~ms}$ earlier in the near- than in the fartarget condition. This target effect is significant for $\mathrm{J}_{\mathrm{A} 1}, \mathrm{~J}_{\mathrm{I} 2}$ and $\mathrm{J}_{\mathrm{A} 2}$ $(p<.05)$ but not for $J_{11}$. Moreover, it does not significantly interact with the two other factors and it has no significant effect on amplitude and duration of jaw strokes.

Altogether, jaw motion is mainly driven by the phonetic goal with different profiles according to the stress position and to the consonant order. The timing of jaw events is also adapted to the finger pointing motion, as showed by the target position effects on jaw timing.
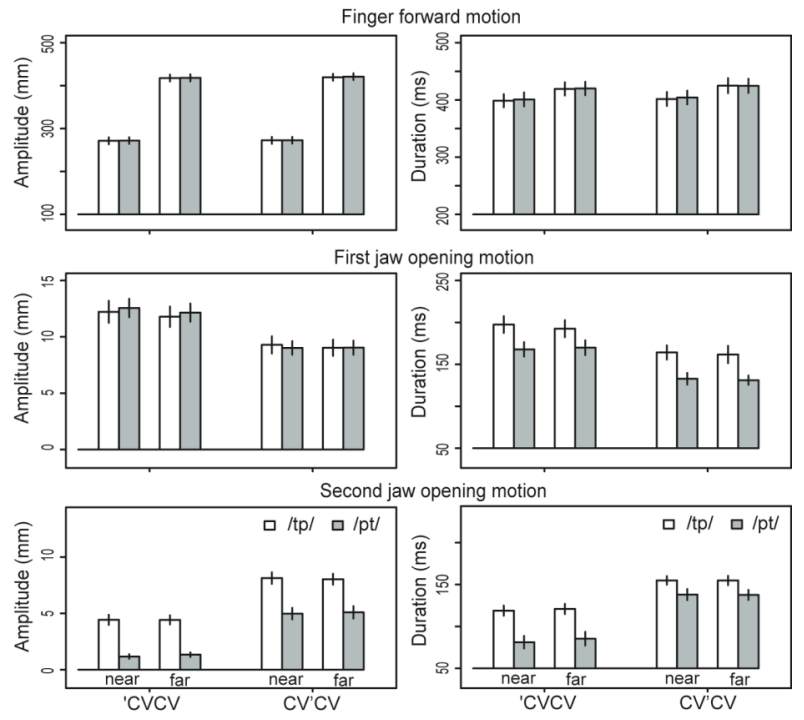

Figure 5. Amplitude and duration of finger forward stroke (top) and of first (middle) and second (bottom) jaw opening strokes according to experimental conditions.

\section{Discussion}

\subsection{A stable jaw-finger coordinative pattern}

Globally, the results confirm those we previously obtained with /papa/ and /tata/ target names [11]. First, the stress position has the same effect on jaw-finger synchronization. The jaw apex for the stressed vowel is included in the period of finger-target alignment. More precisely, for 'CVCV names, the jaw apex for the stressed vowel is aligned with the onset of finger-target alignment. For $\mathrm{CV}^{\prime} \mathrm{CV}$ names, the jaw apex for the stressed vowel is aligned with the end of finger-target alignment. This pattern of synchronization mainly results from both an adaptation of the jaw motion and of the duration for which the finger points to the target. Indeed, jaw response begins earlier for $\mathrm{CV}^{\prime} \mathrm{CV}$ as compared to 'CVCV. This lead makes the second jaw apex closer to the pointing apex. However, it is not enough to make the second jaw apex synchronized with the pointing apex. Consequently, the finger has to stay longer in its apex position for $\mathrm{CV}^{\prime} \mathrm{CV}$ names as compared to 'CVCV ones: it waits for speech focus achievement. This mainly results from the fact that the pointing motion for reaching the target alignment is "target driven": it may begin as soon as possible in order to reach the target. This "externally-driven" system would take priority 
over the "internally-driven" and more flexible speech system, which agrees with previous results [4][14][15].

\subsection{How does jaw motion adapt to the phonetic and deictic requirements?}

The jaw motion is affected by the stress position, the consonant order and the target position. The stress position modifies both the motion timing and parameters. The initiation and apex of opening strokes occur earlier for $\mathrm{CV}^{\prime} \mathrm{CV}$ than for 'CVCV sequences. Unsurprisingly, the duration and amplitude of the first stroke are greater for 'CVCV than for $\mathrm{CV}^{\prime} \mathrm{CV}$ utterances while the reverse is observed for the second stroke. The consonant order affects the initiation times of jaw opening strokes but not their apices times. It also affects the amplitude and duration of jaw strokes with a tendency to observe longer opening strokes for $/ \mathrm{tp} /$ than for $/ \mathrm{pt} /$ and a larger second opening stroke for $/ \mathrm{tp} /$ as compared to /pt/. However these changes do not affect jaw-finger apices synchronization.

The target position mainly affects the timing of jaw motion. The lag of initiation and apex times of the two jaw strokes from the near- to the far- target condition is $10 \mathrm{~ms}$, which is about that observed in [11] and corresponds to the delay of the finger apex from the near- to the far- target. Hence, the increase of target distance induces a translation in time of jaw motion while amplitudes and durations remain the same. This adaptation allows preserving the jaw-finger synchronization pattern for both target positions.

\section{Conclusion}

Taken together, these results agree with the idea of an anchoring of speech focus in pointing gesture in deictic expressions. Moreover, this anchoring seems to be supported by a synchronization of the speech-frame with the sign-frame [8]. This happens to result from two independent levels of speech adaptation. Firstly, the effects of stress position and consonant order indicate an "internal" adaptation of the gestures to the phonetic goal. Secondly, the spatial target effect suggests an "external" adaptation for the synchronization with the pointing motion. These results agree with those obtained on /papa/ and /tata/ sequences [11].

Within the hotly debated topic of the gestural vs. vocal origin of human language [16], recent theories suggest a reconciliation of gestures and vocalisations in proposals where the coordination of sounds and gestures would be a crucial step [1][17]. Future experiments allowing to better understand the coordination of the orofacial and brachiomanual systems in face-to-face communication should provide very important inputs in this framework.

\section{Acknowledgements}

This work is part of the "Patipapa" project funded by the French Ministry of Research (Action Concertée Incitative "Systèmes Complexes en Sciences Humaines et Sociales"). We also wish to thank Christian Abry for his comments on this work.

\section{References}

[1] Abry, C., Vilain A. and Jean-Luc Schwartz J.L. Introduction: Vocalize to Localize? A call for better crosstalk between auditory and visual communication systems researchers: From meerkats to humans. In Abry C., Vilain, A. and Schwartz, J.L., editors, Vocalize to Localize, 313-325, 2005.
[2] Haviland, JB. Pointing, gesture spaces, and mental maps. In McNeill, D., editor, Language and gesture, 13-46, 2000.

[3] McNeill, D. Action, thought and language. Cognition 10: 201208, 1981.

[4] Levelt, W. J. M., Richardson, G. and La Heij, W. Pointing and voicing in deictic expressions. Journal of Memory and Language, 24:133-164, 1985.

[5] Petitto L.A., Holowka S, Sergio L.E. and Ostry D.J. Language rhythms in baby hand movements. Nature, 413: 356, 2001.

[6] MacNeilage, P.F. and Davis B.L. On the origins of internal structure of word forms. Science, 288:527-531, 2000.

[7] MacNeilage, P.F. The frame/content theory of evolution of speech production. Behav. Brain Sci., 21:499-511, 1998.

[8] Ducey-Kaufmann, V., Abry, C. \& Vilain, C. When the Speech Frame meets the Sign Frame in a developmental framework. In Proceedings of Emergence of Language Abilities: Ontogeny and phylogeny, Lyon, 2005.

[9] Pizzuto, E., Capobianco, M., \& Devescovi, A. Gestural-vocal deixis and representational skills in early language development. In C. Abry, A. Vilain \& J.-L. Schwartz (Eds.) Special issue: "Vocalize to Localize II". Interaction Studies. Social Behaviour and Communication in Biological and Artificial Systems, 6 (2), 223252, 2005.

[10] Volterra, V. , Caselli, M. C. , Capirci,O. , Pizzuto, E. Gesture and the emergence and development of language. In M. Tomasello and D. Slobin, (Eds.). Beyond nature-nurture - Essays in honor of Elizabeth Bates. Mahwah, N. J. : Lawrence Erlbaum Associates, pp. 3-40, 2005.

[11] Rochet-Capellan, A., Schwartz J-L., Laboissière, R. and Galván, A., Finger-jaw coordination during a deictic gesture with CVCV utterances: the effect of stress position, in Proceedings of ISSP'2006, 193-200, 2006.

[12] Rochet-Capellan, A. and Schwartz, J.-L. The LabialCoronal effect and CVCV stability during reiterant speech production: An articulatory analysis, in Proceedings of INTERSPEECH-2005, 1013-1016, 2005.

[13] Rochet-Capellan, A. and Schwartz, J.-L. (under revision). An articulatory basis for the Labial-to-Coronal effect: /pata/ seems a more stable articulatory pattern than /tapa/.

[14] Holender, D. Interference between a vocal and a manual response to the samestimuls. In Requin, J. \& Stelmach, G.E., editors, Tutorials in Motor Behavior, 421-432. North Holland Publishing Company, 1980.

[15] Feyereisen, P. The competition between gesture and speech production in dual-task paradigms. Journal of Memory and Language, 36(1):13-33, 1997.

[16] Corballis, M.C. From mouth to hand : Gesture, speech and the evolution of right-handedness. Behavioral and Brain Sciences, 26, 199-260, 2003.

[17] Arbib, M. A. Interweaving protosign and protospeech: Further developments beyond mirror. In C. Abry, A. Vilain \& J.-L. Schwartz (Eds.) Special issue: "Vocalize to Localize II". Interaction Studies. Social Behaviour and Communication in Biological and Artificial Systems, 6 (2), 145-171, 2005. 